\title{
ESTRATÉGIAS DE REFERENCIAÇÃO EM TEXTOS MULTIMODAIS: UMA APLICAÇÃO EM TIRAS CÔMICAS
}

\author{
Paulo Ramos*
}

Resumo: Este artigo se propõe a verificar de que modo os mecanismos de referenciação se processam em textos de cunho multimodal. Parte-se da premissa de que o arcabouco teórico da Linguística Textual pode ser válido também para algumas das produções verbovisuais. As estratégias de produção de sentido serão verificadas em tiras cômicas. A opção por esse gênero ocorre pela peculiaridade de a narrativa ser construida por meio da sucessão de diferentes quadrinhos, o que ajuda a perceber como se processam os mecanismos coesivos num enunciado composto por diferentes modalidades. Selecionaram-se para a análise dez casos de tiras, cinco delas construidas apenas com imagens e as outras cinco com o apoio de elementos verbais escritos e visuais. As séries escolhidas foram Fagundes, de Laerte, e Nico Demo, de Mauricio de Sousa.

Palavras-chave: Referenciação. Multimodalidade. Texto. Tira cômica.

\section{INTRODUÇÃO}

Este século tem inserido no escopo da Linguística Textual diferentes desafios a serem enfrentados teoricamente. Pode-se dizer que a presença de elementos não verbais esteja na agenda dos novos desafios teóricos a serem enfrentados (conforme BENTES; ALVES FILHO; RAMOS, 2010). O assunto já vem sendo citado em algumas das obras teóricas ligadas à área, muitas vezes postulando que abarcar tais produções significa também revisar ou ampliar o próprio conceito de texto.

Ante a ideia de que o texto seria um evento comunicativo em que atuam ações linguísticas, cognitivas e sociais, Marcuschi (2008) entende que tal definição traria algumas implicações. Uma delas é que o conceito de evento comunicativo permitiria ler que se trata de um sistema de conexões entre distintos elementos, de modo que o texto seria

\footnotetext{
* Professor Adjunto da Universidade Federal de São Paulo - UNIFESP. Doutor em Filologia e Língua Portuguesa pela Universidade de São Paulo - USP com pós-doutorado em Linguística pelo Instituto de Estudos da Linguagem da Universidade Estadual de Campinas - UNICAP. Email: contatopauloramos@gmail.com.
} 
construído "numa orientação de multissistemas, ou seja, envolve tanto aspectos linguísticos como não-linguísticos no seu processamento (imagem, música) e o texto se torna em geral multimodal' (2008, p. 80).

No mesmo sentido caminha ponderação feita por Cavalcante (2010). A autora trabalha com o conceito de texto postulado por Koch e o amplia, de modo a abarcar também as produções multimodais. Para tanto, a pesquisadora opta por eliminar a palavra "linguístico" e incluir o termo "não verbal" logo nas primeiras linhas:

A produção de linguagem verbal e não verbal constitui atividade interativa altamente complexa de produção de sentidos que se realiza, evidentemente, com base nos elementos presentes na superfície textual e na sua forma de organização, mas que requer não apenas a mobilização de um vasto conjunto de saberes (enciclopédia), mas a sua reconstrução e a dos próprios sujeitos no momento da interação verbal. (CAVALCANTE, 2010, p. 9)

Além da inclusão dos textos multimodais no escopo dos estudos textuais, há também as implicações disso. Uma delas, talvez a central, seria observar como de dá o processamento textual de tais produções sob o ângulo da Linguística Textual. Uma questão que se lança logo de início é verificar se o escopo teórico aplicado aos enunciados verbais escritos é válido também para os de cunho visual ou verbovisual.

Este artigo se propõe a mostrar que é possível aplicar o conceito de referenciação a textos multimodais, ou ao menos a um deles, as tiras cômicas. Trata-se de um caso peculiar. As tiras cômicas são um texto composto não apenas por elementos de diferentes modalidades, verbal e visual, mas também por uma articulação entre um quadrinho e outro, modo como se constrói a narrativa nas histórias em quadrinhos. A referenciação, portanto, dá-se dentro dos quadrinhos e entre eles, e cabe aos estudos do texto a tarefa de explicitar como se processam os mecanismos de produção do sentido. 


\section{ESTRATÉGIAS DE REFERENCIAÇÃO}

Marcuschi (2008) fala da necessidade de um conhecimento inferencial para o leitor construir as informações implícitas do texto. O autor usa o termo inferenciação para nomear esse processo, construído na atividade sociocognitiva interacional com base nas pistas fornecidas pelo texto. Por isso, o pesquisador vê na inferenciação um vínculo direto com outro processo, a referenciação.

A ideia de referenciação ganhou destaque com os estudos desenvolvidos por Mondada e Dubois (2003). As autoras se contrapõem ao modelo teórico que vê nas palavras uma reprodução exata do mundo, como se fosse um reflexo no espelho. Ocorre o oposto, segundo elas. Em vez de uma estabilidade entre palavra e objeto designado, há no texto uma instabilidade referencial, que varia conforme o ato de enunciação (expressão usada pelas autoras, que reuniria o contexto e as relações interpessoais).

Por esse raciocínio, o referente não é dado, mas construído na interação. Daí a opção de chamar esse processo de referenciação, de modo a evidenciar seu caráter processual. Na visão de Mondada e Dubois, o ato de enunciação cria categorias referenciais, que mudam e se moldam na progressão do texto. São, então, retomadas e recategorizadas durante a produção textual, construindo o que optaram chamar de objetos-de-discurso.

Se falamos, por exemplo, que "a viúva deve ser eliminada", podemos fazer alusão a um suposto assassinato (a tal eliminação) de uma mulher cujo marido já morreu. Colocar a frase num contexto jornalístico adquire sentido diferente. "Viúva" é o jargão utilizado para designar a palavra que aparece sozinha no fim de um parágrafo e que, por questões estéticas, tende a ser retirada na composição visual da notícia. O objetode-discurso nesse último caso é completamente distinto do imaginado inicialmente. Ocorrem, portanto, diferentes categorias referenciais.

Mondada e Dubois admitem que o modelo tradicional ou prototípico tende a ser o primeiro a ser considerado na consolidação dos objetos-de-discurso, mas não o único. Os elementos prototípicos, desde que vistos na perspectiva de instabilidade de categorias, contribuem para a estabilização dos referentes dentro do ato de enunciação, muitas vezes por meio de anáforas. Um exemplo, extraído de reportagem da revista IstoÉ, de 6 de abril de 2005: 
O deputado estadual baiano Sargento Isidório é ex-policial militar. É do PT e incorporou a patente ao seu nome como político. É instrutor de capoeira. Foi feirante e cobrador de ônibus. Aos 43 anos já enfrentou duras vicissitudes da vida, mas nada lhe foi tão duro quanto fazer exame de próstata. "Eu me senti deflorado", disse ele criticando a frieza do médico que, ao final do exame, abriu a porta do consultório e chamou o próximo paciente "como se nada tivesse acontecido". Na terça-feira 29 o Sargento Isidório ocupou durante 25 minutos a tribuna da Assembleia Legislativa, e seu discurso foi, de cabo a rabo, para se lamentar daquilo que classificou como um sentimento de ser "deflorado". O seu exame de próstata foi de manhã, ele discursou à tarde: "Ainda estou vendo estrelas". Mais: o deputado classificou o exame (com o dedo do médico toca a glândula através do ânus para verificar se ela está crescida e se há risco de câncer) de "angustiante" e "desmoralizante para um pai de família".

Um dos objetos-de-discurso centrais do fragmento é instaurado logo no início do texto. Trata-se do deputado estadual Sargento Isidório, categoria que serve de ponto de partida para o processo de leitura. Durante a progressão textual, o referente é recuperado anaforicamente por meio de recategorizações: "ex-policial militar", "instrutor de capoeira", "feirante", "cobrador de ônibus", além de retomadas por meio do pronome "ele", de elipses e de repetições dos termos "Sargento Isidório" e "deputado". A construção da estabilidade nessas várias estratégias de retomada e de recategorização dos objetos-de-discurso é feita, segundo Marcuschi, pela inferenciação.

A recategorização com exigência de inferências é recorrente em textos de humor, que também servem de exemplo para ilustrar esse ponto. Lima (2004) estudou 31 piadas e encontrou nelas 48 ocorrências de recategorização usadas como estratégia para provocar o efeito de humor. Dois casos analisados por ela:

O problema está no freio. Eu vou ter que mexer no burrinho.

O Manuel puxa o garoto para trás e se altera.

Não, senhoire! No garoto, ninguém mexe! 
Um amigo conta pro outro:

Minha sogra caiu do céu!

Ela é maneira assim mesmo?

Não, a vassoura quebrou quando voava sobre a minha casa.

No primeiro exemplo, cria-se uma categoria - "burrinho" - com sentido de peça mecânica. Há recategorização para "burrinho" como sendo garoto burro, em referência ao menino mencionado no texto (o sufixo próprio de diminutivo realça essa leitura). Na segunda piada, "sogra" é vista de maneira prototípica: inicialmente, é a mãe da esposa. No desfecho, é recategorizada como bruxa ou algo como "minha sogra é uma bruxa". Essas estratégias de recategorização, inferidas contextualmente, é o que trazem humor às duas piadas.

Os conceitos de inferenciação, referenciação e objetos-de-discurso enraizaram-se nos estudos da Linguística Textual desenvolvidos no Brasil desde a virada do século. Trabalhos de Marcuschi e Koch (1998), Koch (2004), Koch, Morato e Bentes (2005), Koch e Elias (2006, 2009), Marcuschi (2008) e Cavalcante $(2011,2012)$ são alguns dos que se aprofundaram no assunto e o propagaram no país. É de Cavalcante (2012) a definição de referenciação utilizada neste estudo:

O processo de referenciação pode ser entendido como o conjunto de operações dinâmicas, sociocognitivamente motivadas, efetuadas pelos sujeitos à medida que o discurso se desenvolve, com o intuito de elaborar as experiências vividas e percebidas, a partir da construção compartilhada dos objetos de discurso que garantirão a construção de sentido(s). (CAVALCANTE, 2012, p. 113, grifos da autora)

A questão que pauta estas linhas é que tal arcabouço teórico pode ser válido também para textos multimodais escritos, ou pelo menos parte deles, entre os quais estão incluídas as tiras cômicas, objeto de análise deste artigo. 


\section{TIRAS CÔMICAS}

Ramos (2009, 2011) tem postulado que a tira apresenta um formato regular, em geral horizontal e retangular, com diferentes gêneros autônomos, consolidados nos processos sociocognitivos de interação. $\mathrm{O}$ autor destaca quatro gêneros: 1) tira cômica; 2) tira seriada; 3) tira cômica seriada; 4) tira livre. Os três últimos, por serem pouco difundidos nos cadernos de cultura dos jornais e na internet, tendem a ser pouco conhecidos pelos leitores brasileiros. Antes de nos enfronharmos de vez nas produções de cunho cômico, vale registrar uma rápida síntese das principais marcas de cada um.

Para Ramos, a tira seriada teria como marca central a construção da narrativa por meio de capítulos. Cada tira traria um episódio com um clímax no final, como se fosse uma novela de TV. Na história seguinte, a trama é retomada do ponto onde havia parado. A história se desenrola um pouco mais e instaura um novo suspense, a ser continuado no capítulo seguinte. E assim sucessivamente. Há uma tendência de os temas abordarem aventuras ou mistérios.

A tira cômica seriada teria a característica de apresentar um desfecho inesperado, com duas funções narrativas: criar um efeito de humor no leitor, tendencialmente na cena final, e um gancho para o capítulo da próxima tira. $\mathrm{Na}$ história seguinte, a trama é recuperada e gera nova tirada cômica e novo suspense.

A tira livre é um caso relativamente recente no país, datando de meados da primeira década deste século. Segundo Ramos, tem se difundido por meio dos trabalhos do cartunista Laerte Coutinho no jornal Folha de S.Paulo. O diferencial do gênero, que o tornaria autônomo e estável, seria uma maleabilidade estética e temática. Tal qual uma crônica, usa-se o espaço da tira para experimentação, construindo nele desde uma narrativa com leitura aberta até produções que dialoguem com outras sequências textuais, como a descritiva.

O nosso foco, como já dito, é nas tiras cômicas. Pautadas pelo humor, as tiras cômicas tornaram-se sinônimas de tiras no Brasil. Em estudo sobre o gênero e sobre sua circulação, Ramos (2011) observou que tais produções se assemelham ao modo de composição das piadas. 
O autor elencou um conjunto de características próprias a esse gênero de tira:

- apresenta formato fixo, de uma coluna;

- a tendência é que o formato seja horizontal, de um (mais comum) ou dois andares; em revistas em quadrinhos, pode aparecer também na vertical;

- a tendência é de uso de poucos quadrinhos, dada a limitação do formato (o que constitui narrativas mais curtas); em geral, fica entre um e quatro quadros ou vinhetas;

- a tendência é de uso de imagens desenhadas; há registro de casos que utilizam fotografias, mas são mais raros;

- em jornais, é comum aparecer na parte de cima da tira o título e o nome do autor; em coletâneas feitas em livros e em blogs, essas informações são suprimidas das tiras porque aparecem em geral na capa da obra ou, no circuito de circulação virtual, nas informações sobre o autor em campo específico do site;

- os personagens podem ser fixos ou não;

- há predomínio da sequência narrrativa, com uso de diálogos;

- o tema abordado é humorístico;

- há tendência de criação de um desfecho inesperado, como se fosse "uma piada por dia";

- a narrativa pode ter continuidade temática em outras tiras.

Esta tira da série Rango, de Edgar Vasques, ajuda a ilustrar esses pontos:

Figura 1 - Tira cômica de Rango, de Edgar Vasques

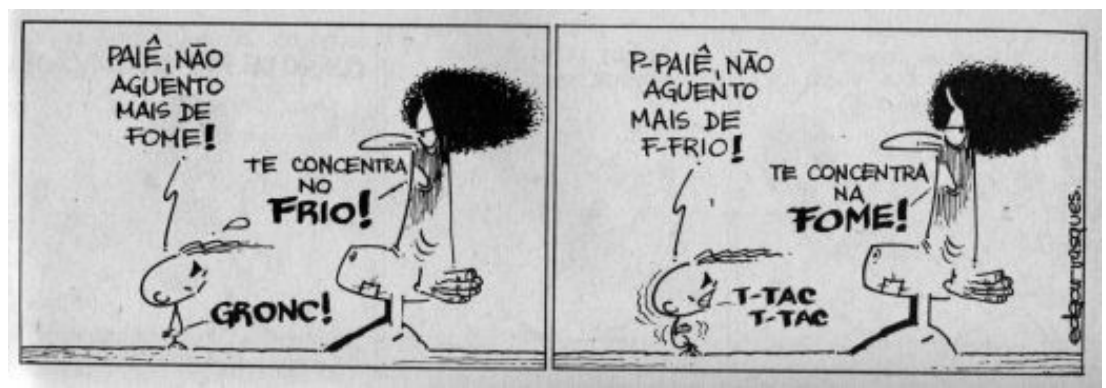

Fonte: Arquivos do autor. 
Em termos composicionais, observa-se o tradicional formato horizontal, composto, no caso, por dois quadrinhos, e o uso de recursos da linguagem das histórias em quadrinhos (apêndice, onomatopeias, linhas cinéticas, que servem para indicar movimento). A cena inicial mostra dois personagens, o protagonista Rango, à direita, e o filho dele. Ao leitor cabe preencher tais informações por conhecimento prévio da série. Outra informação a ser inferida é que ambos vivem num lixão, na miséria, e que, por isso, estão sempre com fome.

No primeiro trecho de fala da tira cômica, o menino diz: "Paiê, não aguento mais de fome!" e ouve como retorno "Te concentra no frio!" (o negrito consta no original). Quase ao mesmo tempo, o estômago do garoto dá como "resposta" um ronco de fome, percebido pela onomatopeia "gronc!" e por um apêndice - espécie de seta que indica fala, som ou pensamento dos personagens - em direção a seu estômago.

O segundo quadrinho mostra os dois personagens nas mesmas posições, mas com sutis mudanças físicas: o menino treme e tenta se proteger do frio com os braços, e o pai olha na direção do leitor. O sentido proporcionado pelas duas imagens é construído com o auxílio da parte verbal, representada por meio dos diálogos.

Ocorre uma inversão do que pai e filho conversaram na cena anterior. Em vez de não aguentar mais de fome, o garoto não suporta, agora, o frio. O pai sugere a ele que, dessa vez, concentre-se na fome para contornar a falta de calor. Ou seja: ambos terão de suportar tanto a fome quanto o frio, porque o pai não tem condições financeiras e sociais de solucionar nem um problema nem outro.

Esse desfecho inesperado, fora do convencional, é o que provoca o sentido de humor, marca da tira cômica e que a assemelha ao gênero piada. Esta também tem como ponto-chave a criação de estratégias verbais que surpreendam o leitor/ouvinte no final da narrativa, conforme atestam estudos de Raskin (1985), Gil (1991), Attardo (1994) e Raskin e Attardo (1994). Embora próximos, os dois gêneros diferem no processamento textual. Pelo fato de as tiras cômicas serem enunciados verbovisuais, elas demandam a articulação das duas modalidades no mecanismo de leitura para a construção do sentido. 


\section{REFERENCIAÇÃO EM TIRAS CÔMICAS}

Como se pôde perceber no exemplo da Figura 1, as tiras cômicas - ou somente tiras, forma sinônima que usaremos a partir deste trecho são compostas por diferentes modalidades: verbal escrita e visual. O processo sociocognitivo interacional de produção de sentido constrói-se, portanto, a partir da soma e da articulação de tais elementos multimodais. Especificamente no caso das tiras, elas apresentam uma peculiaridade comum a outros gêneros das histórias em quadrinhos, o diálogo direto entre as informações verbovisuais presentes entre um quadrinho e outro, estabelecendo entre eles relações de cunho coesivo.

No caso em pauta, o menino e Rango, seu pai, são apresentados na primeira cena e retomados na seguinte, num processo referencial semelhante ao usado nos textos exclusivamente escritos. Em outros termos: constroem-se objetos-de-discurso de ordem visual, que são recuperados anaforicamente na cena seguinte. A existência desse mecanismo nas tiras cômicas já havia sido trabalhada por Ramos (2007, 2009, 2011) e Capistrano (2011). Em todas essas investigações, pode-se perceber como pontos comuns:

- a busca por uma metodologia e por categorias que explicitem os processos de leitura e de produção do sentido em textos multimodais, no caso as tiras cômicas;

- a aplicação do arcabouço teórico da Linguística Textual às produções verbovisuais;

- a inclusão de enunciados multimodais no rol de objetos de análise textual.

Este artigo insere-se nesse contexto e procura explicitar como se podem aplicar as estratégias de referenciação em tiras cômicas, da mesma forma que sinaliza para a possibilidade de uso desse arcabouço teórico em textos multimodais escritos, ou pelo menos no gênero proposto. Para isso, adotaremos dez tiras como recorte para a análise. Optamos por utilizar histórias produzidas por diferentes autores, de modo a tornar mais plural e diversificada a investigação. Para não incorrer em eventuais problemas de tradução, trabalharemos apenas com quadrinistas brasileiros. 
Extraímos as dez tiras cômicas de duas séries diferentes: cinco exemplares da série Nico Demo, de Mauricio de Sousa, e cinco exemplares da série Fagundes, de Laerte. Ambas as séries foram publicadas originalmente em preto-e-branco nos cadernos de cultura dos jornais e, posteriormente, reunidas em livros. Para tornar a seleção o mais aleatória possível, mantivemos como critério o uso de tiras presentes nas primeiras páginas ímpares dos livros que as continham.

A série Nico Demo foi escolhida porque são histórias elaboradas apenas por meio de imagens, sem o uso da parte verbal escrita. Na série Fagundes, ao contrário da anterior, o sentido é construído por meio da articulação das partes verbal escrita e visual. Dessa maneira, podese verificar como se processam os mecanismos referenciais em textos compostos apenas por imagens (caso de Nico Demo) ou que mesclem palavras e imagens (Fagundes). Nosso interesse estará em explicitar tais mecanismos, bem como evidenciar algumas recorrências nesse processo. Também é nosso objetivo observar como se dão as construções de objetos-de-discurso de ordens verbal e visual e como ambos se interrelacionam no processamento textual.

\section{TIRAS SEM PALAVRAS}

A série Nico Demo, de Mauricio de Sousa, foi criada para dialogar com um leitor mais maduro, público diferente do que o quadrinista tradicionalmente atingia, o infantil, com as histórias da Turma da Mônica. O personagem-título começou a ser publicado em 1966 no Jornal da Tarde e se caracterizava por agir de maneira pouco usual, muitas vezes de forma mórbida e jocosa. Além das atitudes pouco convencionais do menino protagonista, outra marca da tira era a de não possuir balões. Poucas das histórias da série foram produzidas com o apoio da modalidade verbal escrita.

Visto que a série é cunhada apenas no aspecto visual, a produção do sentido tem de ser feita apenas com o apoio das imagens e da articulação entre as informações levadas de uma cena para outra. Nos exemplos pesquisados, todas as tiras apresentaram mais de um quadrinho: três delas com um trio de quadrinhos e duas com um quarteto. Os casos analisados também apresentavam um desfecho inesperado, que levava ao humor. 
No tocante à referenciação, os objetos-de-discurso são instaurados por meio dos desenhos criados pelo autor da tira e recuperados pelo leitor na interação sociocognitiva.

Vejamos o primeiro caso:

Figura 2 - Nico Demo, de Mauricio de Sousa
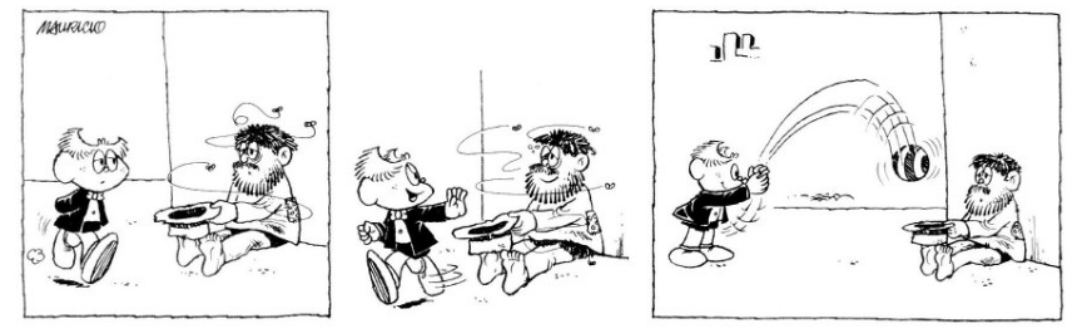

Fonte: Sousa (2011)

A narrativa foi dividida em três quadrinhos. No primeiro, destacam-se três objetos-de-discurso, todos construídos no texto: 1) Nico Demo, o protagonista da série, informação recuperada via conhecimentos prévio e compartilhado; 2) um pedinte, dado que é consolidado por meio da associação da roupa e das moscas em torno do corpo dele (indicando sujeira ou mau cheiro) com o chapéu à mostra; 3) o chapéu em si, erguido por uma das mãos, o que socialmente é visto como gesto de pedido de dinheiro.

Após o contato inicial entre os dois personagens, ambos são retomados anaforicamente no quadrinho seguinte. Nico Demo sugere com a mão esquerda que o pedinte aguarde um pouco. Este demonstra aparente felicidade, pelo que se observa pelos olhos e pelo sorriso. Podese dizer, com base nessas nuances visuais, que houve uma retomada dos objetos, mas a eles foi acrescida uma predicação de ordem imagética (gesto da mão, semblante feliz).

A cena final apresenta a estratégia textual que levará ao efeito de humor. Em vez de trazer dinheiro ou algo que pudesse ajudar o pedinte, Nico Demo aparece com uma bola e a arremessa em direção ao chapéu, 
como se este fosse um aro de basquete. Do ponto de vista da referenciação, o chapéu é recategorizado: deixa de ser um instrumento para pedir dinheiro e funciona como receptáculo para a bola. Essa situação inusitada é a chave para a comicidade da tira.

Outro dos cinco exemplos selecionados apresenta situação semelhante:

\section{Figura 3 - Nico Demo}
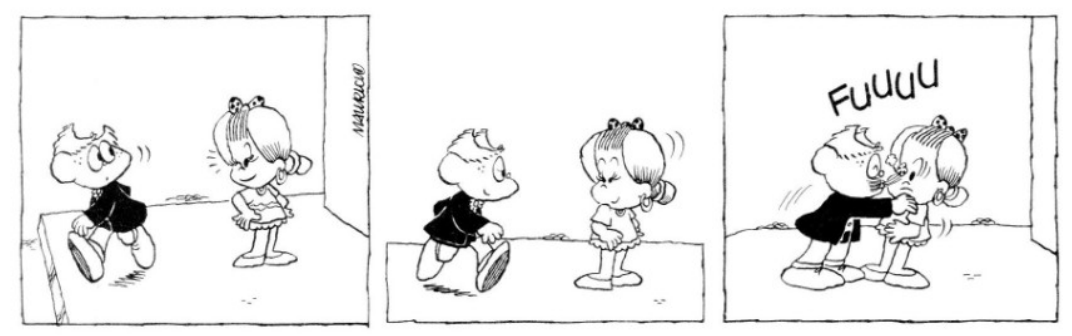

Fonte: Sousa (2011)

Uma vez mais, instauram-se os objetos-de-discurso visuais na cena inicial. Além do protagonista, há também uma menina, que dá a ele uma piscadela. Sociocognitivamente, piscar para alguém é entendido como um gesto de paquera. O quadrinho seguinte mostra Nico Demo caminhando em direção a ela, sugerindo que demonstrou interesse pelo flerte.

O desfecho quebra essa expectativa narrativa, algo próprio ao gênero: o personagem se aproxima do rosto da garota e assopra o olho dela. O objeto "piscadela" é recategorizado: deixa de ser algo vinculado a uma atitude ligada a relacionamentos e se torna uma reação física à presença de ć́lio no olho. O sopro seria uma maneira de livrar o fio de dentro do olho da menina.

Os três outros exemplos da série de Mauricio de Sousa se assemelham na questão de instaurar os objetos-de-discurso nas cenas iniciais, mas diferem no modo como é construído o desfecho. No lugar de uma recategorização, ocorre a instauração de um novo referente, inexistente até então. Vejamos essas situações: 
Figura 4 - Na tira de Nico Demo, instaura-se novo objeto-de-discurso no final
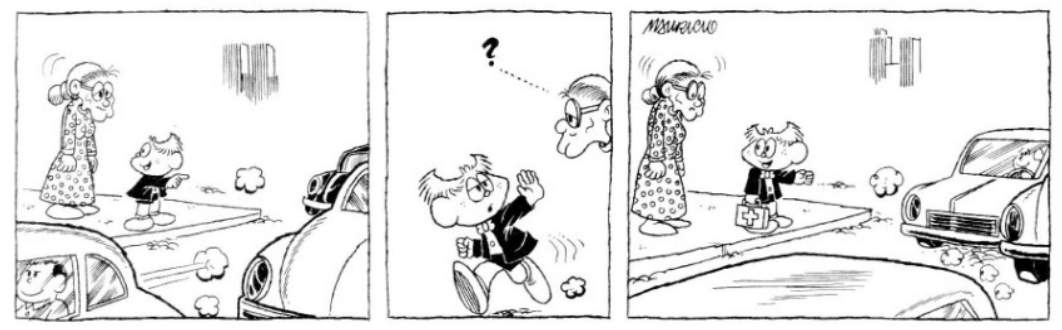

Fonte: Sousa (2011)

O personagem-título aparece na cena inicial ao lado de uma senhora idosa e diante de uma avenida movimentada (os objetos-dediscurso instaurados). Pelo que se depreende do gesto dele, Nico Demo iria oferecer ajuda para que ela pudesse atravessar a pista. Assim como no caso da Figura 2, ele sinaliza com mão para que a mulher o aguarde. A solução, por assim dizer, aparece na cena final, por meio de um objeto-de-discurso novo: uma caixa de primeiros-socorros. A proposta do personagem não era ajudar a senhora a cruzar a rua, mas fornecer a ela material médico caso se acidente no processo de travessia.

O objeto-de-discurso novo, inesperado no percurso da narrativa, é o que leva ao efeito de humor. Ocorrem outras duas situações assim nas figuras 5 e 6 .

Observamos na Figura 5 que há uma troca de referentes entre a cena inaugural e a final. O piloto da lancha afunda com o barco (o naufrágio é o objeto-de-discurso novo). Nico Demo, em vez de acenar para quem conduzia a embarcação, pega um lenço (outro objeto instaurado) para dar o último adeus ao condutor enquanto ele submerge.

$\mathrm{Na}$ Figura 6, a novidade que surge no último quadrinho é um homem calvo, que lê um jornal sentado ao ar livre. Este objeto, apresentado no desfecho, é a chave para a construção da situação cômica: cairia na cabeça dele a bituca de cigarro encontrada pelo protagonista da série e que foi jogada por cima do muro para que nenhuma pessoa descalça pudesse pisar nela e se queimar (informação apresentada visualmente dentro de um balão, presente no segundo quadrinho). 
Figuras 5 e 6 - Duas tiras cômicas de Nico Demo
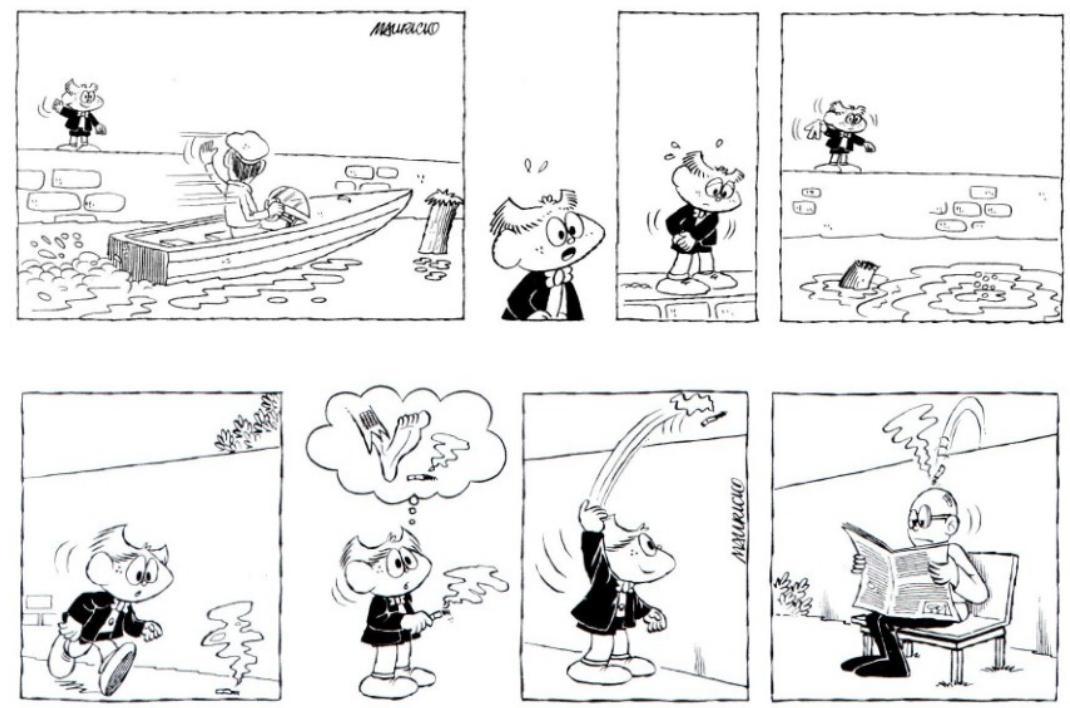

Fonte: Sousa (2011)

O resultado parcial da análise permite reforçar que foi possível a construção do sentido textual apenas por meio das imagens, sem o auxílio da parte verbal escrita. No mecanismo referencial, envolveram-se elementos inferenciais (não só nas informações dentro dos quadrinhos como também no corte entre uma cena e outra) e referenciais. Estes, em particular, puderam ser costurados e trabalhados de maneira semelhante à que a Linguística Textual trabalha os enunciados escritos, com objetosde-discurso instaurados, retomados, recategorizados.

\section{TIRAS VERBOVISUAIS}

As tiras de Fagundes apresentam tanto elementos verbais escritos como visuais, modo de produção da maior parte das tiras cômicas brasileiras. Criadas por Laerte e publicadas no jornal Folha de S.Paulo durante a década de 1990, as histórias mostram um funcionário que tem 
como objetivo de vida bajular os outros, em especial seu chefe - que tenta fugir dele, tamanha a obsessão. Por essas atitudes, é costumeiramente chamado de "puxa-saco".

Das cinco tiras selecionadas para esta análise, duas foram elaboradas em quatro quadrinhos, duas com três e uma com apenas um quadro. Começamos por esta:

Figura 7 - Tira de Fagundes, narrada em um único quadrinho

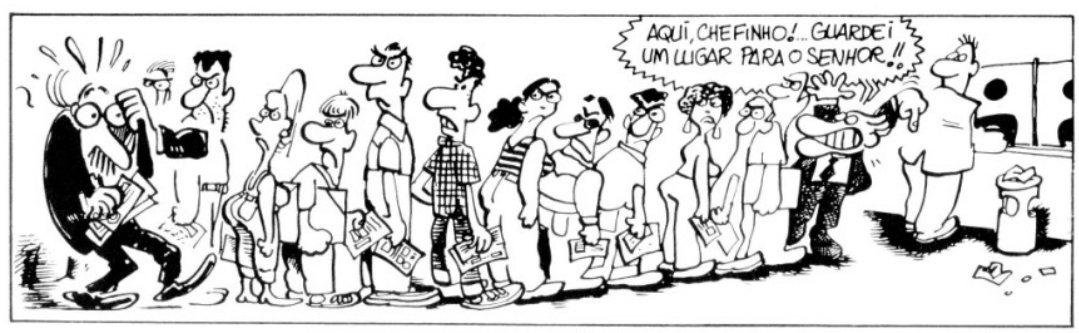

Fonte: Laerte (1991)

Como se pode constatar, é possível condensar os elementos narrativos mínimos numa única cena. Os desenhos instauram três objetos-de-discurso centrais: Fagundes, à direita, percebido por mecanismos inferenciais; o chefe dele, à esquerda; entre ambos, uma fila formada por mais de dez pessoas, que olham com feições zangadas para o chefe. O motivo do incômodo é revelado pelo balão de fala do funcionário bajulador: "Aqui, chefinho!... Guardei um lugar para o senhor". Como o chefinho é o último da fila, ele passaria à frente de todos os demais, o que justificaria o estranhamento.

À luz dos processos de referenciação, há de se destacar dois pontos sobre essa tira. O primeiro é que o objeto-de-discurso chefe/chefinho é construído não só pelo elemento visual, mas também pelo verbal, posto que o termo aparece na fala do personagem Fagundes. Percebe-se, portanto, uma junção das duas formas referenciais para o mesmo objeto. O segundo ponto a ser destacado é o dedo do funcionário apontar para o que seria o início da fila, sentido corroborado pela expressão "um lugar para o senhor". Ocorre aí um recurso dêitico, que reforça a parte verbal. 
Outro exemplo da série apresenta recursos de referenciação semelhantes:

Figura 8 - Segunda tira de Fagundes, de Laerte
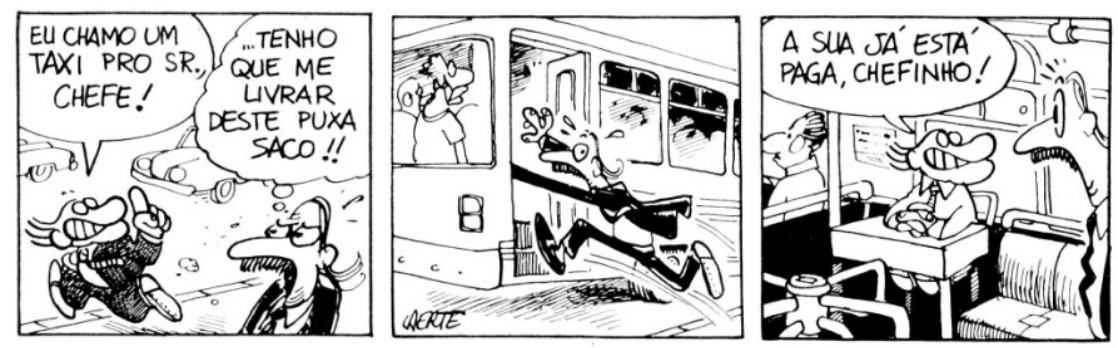

Fonte: Laerte (1991)

Ao contrário do exemplo anterior, este é narrado em três quadros. No primeiro, instauram-se os objetos-de-discurso visuais Fagundes e chefe. Este é reforçado tanto pelo desenho do personagem quanto pelo aspecto verbal, contido no balão: "Eu chamo um táxi pro sr., chefe!". Quanto ao funcionário, percebe-se visualmente que se trata de Fagundes, que recebe verbalmente a predicação "puxa saco" pelo patrão.

O segundo quadrinho serve de transição para o desfecho. Tentando fugir do assédio do funcionário, o chefe se refugia num ônibus, referente que passa a ser instaurado a partir de então. A cena final mostra Fagundes dentro do coletivo, no papel de cobrador. Ele diz ao chefe, espantado: “A sua já está paga, chefinho". Infere-se, pela frase e pelas informações visuais, que seja a passagem que já esteja paga. Verbalmente, há ainda uma retomada do objeto-de-discurso ("chefinho").

Outras duas tiras selecionadas da série apresentam processamento textual muito próximo, como se pode verificar a seguir: 
Figuras 9 e 10 - Terceira e quarta tira de Fagundes
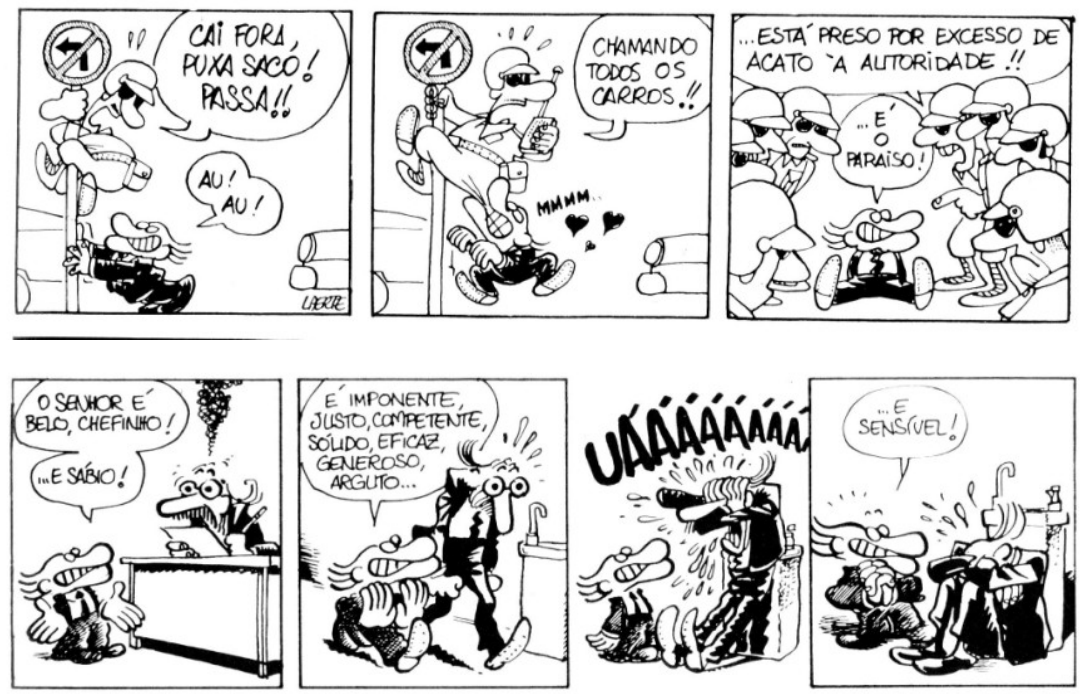

Fonte: Laerte (1991)

Vê-se, no primeiro caso, que se apresentam os objetos-de-discurso visuais Fagundes e um policial, este percebido por meio das roupas. Fagundes é construído como se agisse como um cachorro - o que faz o oficial se proteger num poste de placa de sinalização (outro objeto instaurado). No segundo quadrinho, diante da mordida que recebe, o policial pede por reforços ("Chamando todos os carros", diz no balão). A cena final revela o humor: Fagundes é preso por "excesso de acato à autoridade" e vê nisso algo positivo, "o paraíso", por estar rodeado de outros oficiais da lei, instaurados apenas no desfecho.

O exemplo da Figura 10 retoma visualmente, ao longo dos quatro quadrinhos, os dois objetos-de-discurso instaurados visualmente na primeira cena: uma vez mais Fagundes e chefe/chefinho. Trabalha-se bastante com a predicação verbal e visual. Nos balões, o funcionário elenca as qualidades do patrão: belo, sábio, imponente, justo, competente, sólido, eficaz, generoso, arguto, sensível. Esta última característica é revelada apenas no final, após o chefe ter uma crise de 
choro - predicação construída de forma visual - ao ouvir tantos elogios do colega bajulador.

O exemplo final, dos cinco casos selecionados para esta análise, difere no processamento dos referentes se comparado aos demais:

Figura 11 - Quinta tira de Fagundes, de Laerte
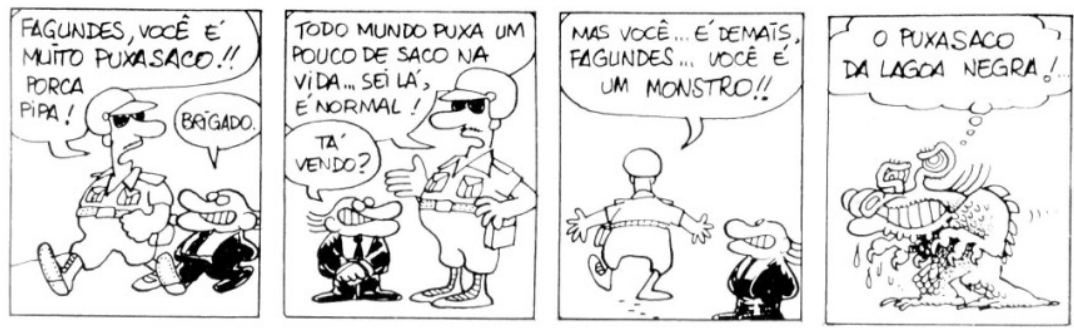

Fonte: Laerte (1991)

Há dois objetos-de-discurso visuais, Fagundes e policial, instaurados no primeiro quadrinho e retomados nos dois seguintes. $\mathrm{O}$ diálogo entre eles revela o tema da conversa: o fato de Fagundes ser excessivamente "puxa-saco". Por conta dessa característica, o oficial o classifica como "monstro". O diferencial dessa tira é visto na cena final: o objeto Fagundes é recategorizado como monstro também imageticamente. O autor da história o desenha de maneira disforme, configurando o que seria o "puxa caso da Lagoa Negra". O desfecho inusitado construiria o efeito de humor.

\section{CONSIDERAÇÕES FINAIS}

O objetivo central neste artigo foi demonstrar que estratégias de referenciação, utilizadas em textos escritos, podem ser válidas também para produções multimodais. Utilizamos como recorte tiras cômicas extraídas de duas séries, criadas por diferentes autores: Nico Demo e Fagundes. A opção pela seleção de ambas foi o fato de uma ser desenvolvida apenas com o uso das imagens (Nico Demo) e a outra com a mescla das modalidades verbal escrita e visual (Fagundes). 
Foi possível aplicar o arcabouço teórico da Linguística Textual nos dez casos selecionados. Os mecanismos de instauração, retomada e recategorização de objetos-de-discurso se deram tanto no aspecto verbal quanto no visual. Em algumas situações, como as vistas nas figuras $8 \mathrm{e}$ 10, pode haver uma convergência dos referentes imagéticos e verbais, ambos sinalizando para os mesmos objetos. Em outros termos: pelo menos no gênero trabalhado, foi possível desenvolver a análise sob a luz dos princípios teóricos ligados ao texto.

Outras duas constatações merecem registro. A primeira é que tal mecanismo teórico de análise auxilia a abordagem de produções construídas exclusivamente por imagens, caso das tiras das figuras 2 a 6 . A segunda constatação é que o processamento anafórico dos objetos-dediscurso, com sucessivas retomadas e recategorizações, é particularmente relevante para explicar a construção do sentido em histórias em quadrinhos, cujas narrativas se pautam na sucessiva troca de quadros recurso que ocorreu em nove das dez tiras selecionadas para este estudo.

A leitura e a análise de produções multimodais sob o olhar da Linguística Textual ainda está longe de ser esgotado. Entre os próximos passos, está a aplicação do mecanismo teórico a trabalhos de diferentes gêneros, de modo a verificar compatibilidades e eventual necessidade de apoio teórico de outras áreas. Entretanto, pode-se concordar, desde já, com um alargamento do conceito de texto, de modo a abarcar também os enunciados de cunho visual e multimodal, como as tiras cômicas analisadas nestas linhas.

\section{REFERÊNCIAS}

ATTARDO, S. Linguistic theories of humor. Berlin/New York: Mouton de Gruyter, 1994.

; RASKIN, V. Script theory revis(it)ed: joke similarity and joke representacion model. Humor - Internacional journal of humor research, Berlin/New York, v. 7, n. 1, p. 27-54, 1994.

BENTES, A. C.; ALVES FILHO, F.; RAMOS, P. Enfrentando desafios no campo de estudos do Texto. In: BENTES, A. C.; LEITE, M. Q. (Orgs.).

Linguística de Texto e Análise da Conversação: panorama das pesquisas no Brasil. São Paulo: Cortez, 2010. p. 389-428. 
CAVALCANTE, M. M.; CUSTÓDIO FILHO, V. Revisitando o estatuto do texto. Revista do GELNE, v. 12, n. 2, 2010.

2011.

. Referenciação: sobre coisas ditas e não ditas. Fortaleza: Edições UFC,

. Os sentidos do texto. São Paulo: Contexto, 2012.

CAPISTRANO, R. Ler e compreender tirinhas. In: ELIAS, V. M. (Org.). Ensino de lingua portuguesa: oralidade, escrita e leitura. São Paulo: Contexto, 2011. p. 227235.

GIL, C. M. C. A linguagem da surpresa: uma proposta para o estudo da piada. 1991. 220f. Tese (Doutorado em Letras Clássicas e Vernáculas). Faculdade de Filosofia, Letras e Ciências Humanas, Universidade de São Paulo, 1991

KOCH, I. V. Introdução à Linguistica Textual. São Paulo: Martins Fontes, 2004. ; MARCUSCHI, L. A. Processos de referenciação na produção discursiva. D.E.L.T.A., v. 14, p. 169-190, 1998.

KOCH, I. V.; MORATO, E. M.; BENTES, A. C. (Orgs.). Referenciação e discurso. São Paulo: Contexto, 2005.

KOCH, I. V.; ELIAS, V. M. Ler e compreender os sentidos do texto. São Paulo: Contexto, 2006. . Ler e escrever: estratégias de produção textual. São Paulo: Contexto, 2009.

LAERTE. Fagundes: um puxa-saco de mão cheia. São Paulo: Circo/Nova Sampa, 1991. (Coleção Circo, v. 1).

LIMA, S. M. C. A construção dos sentidos do texto bumoristico: uma abordagem linguístico-cognitiva. Protexto: Grupo de Pesquisa em Lingüística/ UFC. 2004. CD-ROM.

MARCUSCHI, L. A. Produção textual, análise de gêneros e compreensão. São Paulo: Parábola, 2008. (Coleção Educação Linguística, v. 2).

MONDADA, L.; DUBOIS, D. Construção dos objetos de discurso e categorização: uma abordagem dos processos de referenciação. In:

CAVALCANTE, M. M.; RODRIGUES, B. B.; CIULLA, A. (Orgs.). Referenciação. São Paulo: Contexto, 2003. p. 17-52.

RAMOS, P. Tiras e piadas: duas leituras, um efeito de humor. 2007. 224f. Tese (Doutorado em Letras). Faculdade de Filosofia, Letras e Ciências Humanas, Universidade de São Paulo, 2007. 
. A leitura dos quadrinhos. São Paulo: Contexto, 2009.

. Faces do humor: uma aproximação entre piadas e tiras. Campinas, SP:

Zarabatana Books, 2011.

RASKIN, V. Semantic mechanisms of humor. Holland: D. Reidel Publishing Company, 1985.

SOUSA, M. de. Nico Demo: aí vem encrenca. Porto Alegre: L\&PM, 2011. (Coleção L\&PM Pocket; v. 996).

Recebido em: 30/07/12. Aprovado em: 30/10/12.

Title: Referential strategies in multimodal texts: a study in comic strips

Author: Paulo Ramos

Abstract: This article aims to verify how referential strategies are processed in multimodal texts. It starts with the premise that the theoretical framework of Textual Linguistics may be valid also for some of the verbal-visual productions. The strategies of meaning production will be verified in comic strips. The choice for this genre is due to its peculiarity of having the narrative constructed by the succession of different scenes, which helps to understand how the mechanisms are processed in a cohesive statement made by different methods. Ten cases were selected for the analysis of comic strips, five of them built only with images and five others with the support of written verbal and visual elements. The series chosen were Fagundes, created by Laerte, and Nico Demo, from Mauricio de Sousa.

Keywords: Referential strategies. Multimodality. Text. Comic strip.

Titulo: Estrategias de referenciación en textos multimodales: una aplicación en viñetas cómicas Autor: Paulo Ramos

Resumen: Este articulo se propone verificar de que modo los mecanismos de referenciación se procesan en textos de cuño multimodal. Se parte de la premisa de que el esquema teórico de la Lingüistica Textual puede ser válido también para algunas de las producciones verbovisuales. Las estrategias de producción de sentido serán verificadas en viñetas cómicas. La opción por ese género ocurre por la peculiaridad de la narrativa ser construida por medio de la sucesión de diferentes cuados, lo que ayuda a percibir como se procesan los mecanismos cohesivos en un enunciado compuesto por diferentes modalidades. Se seleccionaron para el análisis diez casos de viñetas, cinco de ellas construidas apenas con imágenes y las otras cinco con el apoyo de elementos verbales escritos y visuales. Las series elegidas fueron Fagundes, de Laerte, y Nico Demo, de Mauricio de Sousa.

Palabras-clave: Referenciación. Multimodalidad. Texto. Viñeta cómica.

RAMOS - Estratégias de referenciação... 